\title{
Praxistipp
}

\section{Umgang mit alternden Therapiepferden}

\section{Marianne Gäng}

\section{Mein Therapiepferd wird alt: Was nun?}

Diese Frage muss sich jeder verantwortungsbewusste Pferdebesitzer einmal stellen. Hier ein paar bedenkenswerte Überlegungen dazu.

Wer über die körperlichen und die psychischen Alterungserscheinungen seines Pferdes Bescheid weiß, kann ihm helfen - ihm, und sich selbst damit auch, indem er sich und sein Pferd rechtzeitig auf diesen Lebensumstand vorbereitet.

Alternde Pferde haben spezielle Bedürfnisse, welche deutlich über die ordentliche Fütterung und Pflege hinausgehen. Zu denken ist hier an psychische Aspekte des Älterwerdens generell vergleichbar beim Menschen z.B. nach der Pensionierung mit dem Wegfall der Berufsarbeit.

Aber auch ein Pferd kann Probleme bekommen, wenn es - aus welchen Gründen auch immer abrupt „pensioniert" oder „aufs Altenteil“ gesetzt wird. Ein Therapiepferd, welches sein bisheriges Leben für und mit Menschen in enger und vertrauter Beziehung verbracht hat, sollte den Lebensabend nicht "einfach so" auf einer Weide mit ihm fremden Artgenossen verbringen müssen.

Ob es seinen letzten Lebensabschnitt pferdegemäß verbringen kann, hängt auch direkt von seinem Umfeld ab. Es braucht eine Umgebung, in der es sich wohl fühlt, die ihm Sicherheit gibt, ihm vertraut ist, wo es sich nicht fürchten muss. Es braucht vertraute Artgenossen, mit denen es freundschaftlich kraulen kann. Alte Pferde brauchen das Kraulen besonders, weil ihnen das eigene Wälzen auf dem und über den Rücken zunehmend schwerer fällt. Hinlegen und sich ausruhen, dann mühsam wieder aufstehen: All das tut ein altes Pferd nur in vertrauter Umgebung.

Woran aber merke ich, dass mein Pferd alt wird, altersbedingt verändert ist? Dem aufmerksamen Pferdebesitzer künden sich als leise Vorboten des Alterns schwankende Leistungsfähigkeit und Leistungsbereitschaft an: Das Pferd verträgt z. B. den einen oder anderen Klienten nicht mehr oder weicht ihm aus, wird schneller ungeduldig. Oft auch ist in der Vorbereitungsphase auf eine Therapiestunde beim Pferd eine stärkere, zunehmende Steifheit zu beobachten: Galle an den Fesselgelenken, Spat am Sprunggelenk, Taktunklarheiten beim Gehen. Anfänglich mögen das zwar nur kleine Unpässlichkeiten sein, wie wir Menschen sie auch bei uns selbst feststellen. Als Verantwortliche sollten wir sie aber beachten, sonst werden wir eines Tages „böse Überraschungen“ erleben! Das Pferd allerdings wird weniger überrascht, es hat den allmählichen Alterungsprozess schon viel früher gespürt.

Ein Therapiepferd hat in seinem Leben meist mehrere Betreuer, die es oft nicht sehr gut kennen und dadurch zu seinen Ungunsten Wichtiges übersehen oder verpassen. Das Pferd kann sich kaum wehren, wenn es sich schwach fühlt und leicht ermüdet. Wenn es dennoch ohne Rücksicht auf seinen Zustand gefordert wird, endet sein Leben durch Überforderung leider oft frühzeitig. 
übrigen Geschehen ihr Hinterteil zu, blickte still über die Weiden in die Ferne oder träumte vor sich hin. Sie liebte es immer noch, wenn ich sie ansprach, ausgiebig kraulte und sie dann zusammen mit unserem Hund auf einen kürzeren Spaziergang in die Umgebung mitnahm. Hier und da blieb sie stehen, knabberte Gras und ließ sich streicheln.

Aber die Zeit stand nicht still. Der kontrollierende Tierarzt, ein Freund unseres Hauses, diagnostizierte eine Krebserkrankung. Nun wussten wir, dass Héla uns bald verlassen würde. Auf der Weide bei unserem Haus wurde sie im Spätsommer erlöst. In unserm Herzen bleibt Héla unvergessen lebendig. Bilder zum Therapieeinsatz von Héla sind im Buch „Heilpädagogisches Reiten und Voltigieren“ (Gäng 2010) zu finden.

PS: Ich würde mich über Leser-Berichte in der MuP freuen, z. B. über eigene Erfahrungen um den altersgerechten Einsatz von Pferden im HPR.

\section{Literatur}

Gäng, M. (2010): Heilpädagogisches Reiten und Voltigieren. 6. Aufl. Ernst Reinhardt, München/Basel

Over, U. (1999): Mein Pferd wird alt. Müller Rüschlikon, Stuttgart

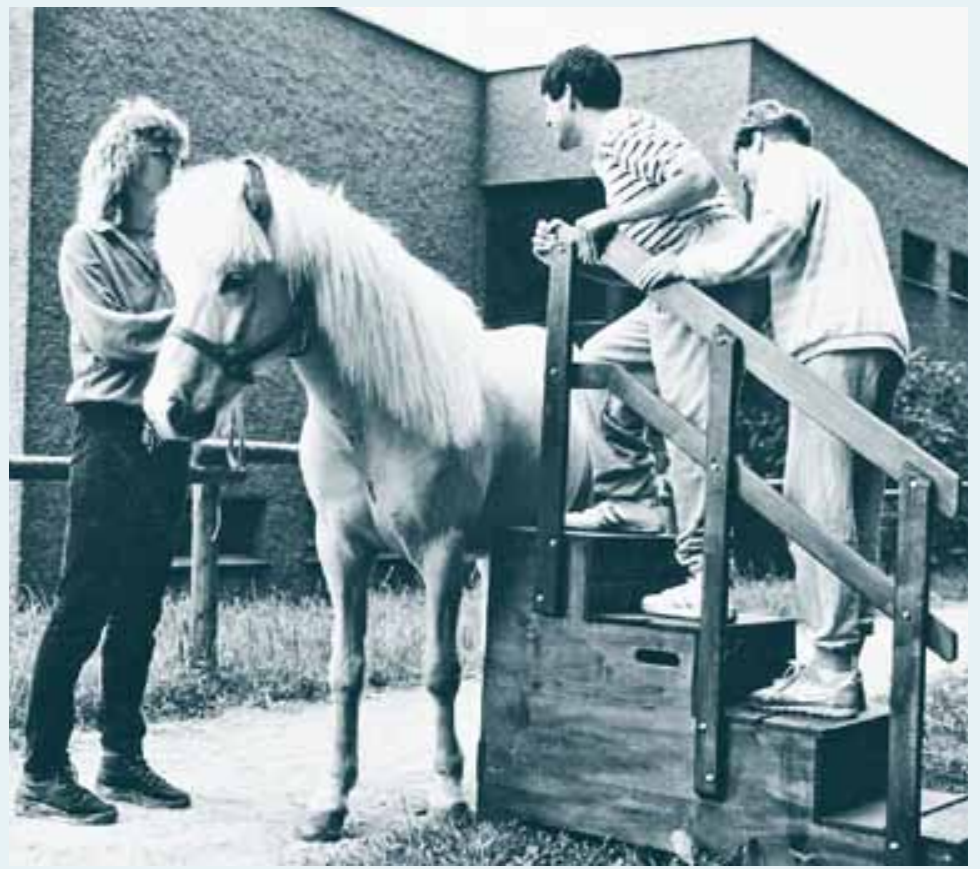

\section{Die Autorin}

\section{Marianne Gäng}

Verantwortliche im COLLEGIUM für Ausbildung SG-TR, Schweizer Gruppe Therapeutisches Reiten.

\section{Anschrift:}

Marianne Gäng

Hofackerstr. $6 \cdot \mathrm{CH}-4118$ Rodersdorf

spoi@bluewin.ch

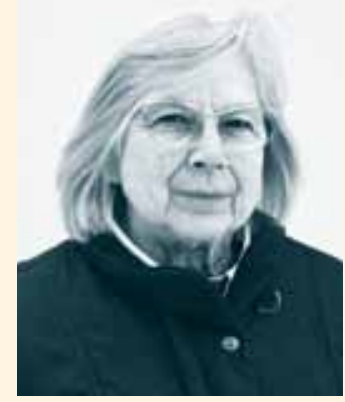

